\title{
Assessment of Learning Outcomes
}

\author{
Hamish Coates
}

\section{Introduction}

Through a strategic analysis of assessment in higher education, this chapter clarifies rationales for assessment reform, critically evaluates progress to date, reviews knots tangling progress, and highlights change opportunities. The analysis concludes by advancing the need for serious work on assessment redesign that funnels improvement investments in the most effective ways. Taking stock of research and framed for a specific policy purpose, this chapter is necessarily brief and lightly referenced. Readers are referred to Coates (2014) for a more comprehensive treatment of major topics.

The assessment of higher education student learning outcomes is very important. Assessment provides essential assurance to a wide variety of stakeholders that people have attained various knowledge and skills, and that they are ready for employment or further study. More broadly, assessment signposts, often in a highly distilled way, the character of an institution and its educational programs. Much assessment is expensive, making it an important focus for analysis. Assessment shapes education and how people learn in powerful direct and also indirect ways. Of course, assessment is highly relevant to individuals, often playing a major role in defining life chances and directions.

Given such significance it is surprising that much assessment in higher education has not changed materially for a very long time, and that economically and technically unsustainable practice is rife. While there are, of course, an enormous number of innovative and high-quality developments, including those associated with technology advances, everyday around the world students still write exams using pen and paper, sitting in large halls at small desks in rows without talking. It is possible that this reflects the pinnacle of assessment, but given the lack of

H. Coates $(\bowtie)$

Centre for the Study of Higher Education, The University of Melbourne, Parkville, Australia

e-mail: hamishc@unimelb.edu.au

(C) The Author(s) 2015

A. Curaj et al. (eds.), The European Higher Education Area,

DOI 10.1007/978-3-319-20877-0_26 
reflective technological advance over an extended period, this seems unlikely. Rather, given the enormous changes reshaping core facets of higher education, and pressures and prospects surrounding assessment, it is more likely that the 'transformational moment' has yet to come. As this chapter portends, however, with the right investment and intellect the revolution may be closer than ever.

This chapter provides contemporary insights into the assessment of higher education learning outcomes, surveying recent progress and clarifying prospects for further transformational advance. It begins by recapping rationales for reforming this facet of higher education. It then takes stock of progress through an evaluative review of several prominent assessment initiatives. While far from exhaustive, this review highlights the broad scope and pretext for growth. Two subsequent sections help channel future energy. First, using risk-assessment logic, the chapter reviews what would appear to be the major change blockers. Second, a broad cost/benefit logic is deployed to identify specific options for development. With these analyses to hand, the chapter concludes by advancing a program of assessment redesign, and sketching initial tactics for its development.

Assessment is a broad area, and this analysis could be progressed in a variety of ways, so it is helpful to clarify scope and assumptions. The term 'assessment' is interpreted very broadly as involving the measurement, reporting and interpretation of student learning and development. The analysis embraces formative and summative assessment, and ranges from in-class to cross-national practice, but emphasis is placed on formal assessment that is relevant to establishing the quality of individual learning. The analysis is pitched to be policy relevant regardless of whether local or large-scale practice is being addressed. Attention is focused specifically on assessment, rather than on a host of surrounding activities such as curriculum design, quality assurance or funding, though these are undoubtedly relevant and must be factored into any extended analysis. As these introductory remarks convey, the chapter adopts a critical stance in which it is assumed that assessment must be improved. It is assumed that the continued use of proxy measures for outcomes like statistics on graduate employment or further graduate study, or the use of qualification/organisation-level accreditation in place of robust measures of individual competence, is unsatisfactory (for analysis see: Coates 2010). The analysis is driven by a general desire to improve both the quality and productivity of education. To strengthen higher education, it is assumed that assessment must be done better and more efficiently, and it is assumed transparency plays an important role in this.

Throughout this chapter, mention is made to 'routine', or 'conventional', or 'traditional' assessment practice. This refers to a vast range of activities which are helpful to clarify at the outset given that this chapter is framed as a critique. Broadly, such assessment can be caricatured as involving academics working alone, and within single institutions to produce technically non-validated assessment materials that map to arbitrary parts of the curriculum of a single subject. Such assessment might be delivered in formats and practices unchanged for many decades, scored normatively by different markers without rubrics or training, analysed using basic additive methods, adjusted to fit percentile distributions, then reported 
using grades that offer thin feedback. It is assumed that together these attributes give rise to a syndrome which constricts the advance of higher education. Of course this is an accentuated and overly negative picture, and innovative and excellent practice abounds, but elements of such practice remain regrettably rife across all fields, including those which are subject to professional accreditation.

\section{A Growing Imperative for Transforming Assessment}

In most countries university education is in demand like never before. Yet many traditional approaches to higher education do not scale well, challenging the quality and productivity of supply. Meeting greater demand increasingly requires new and different ways of doing education. Also, as higher education expands and diversifies, more energy must be invested in ensuring that sufficient learning has been achieved to warrant the award of a qualification. Yet assessment would appear to be one of the final change frontiers in the contemporary reconfiguration of higher education. Much assessment has not changed for a century, yet other facets of education have transformed, and student learning is subjected to increasing scrutiny. To launch the discussion and frame subsequent analysis, it is helpful to explore imperatives for reforming the assessment of learning outcomes. The summary presented here draws on much more extensive analysis elsewhere (Coates 2014; Coates and Mahat 2013, 2014), and necessarily takes for granted broader changes taking place in many higher education systems.

First, there is value in advancing assessment in the spirit of continuous improvement. There are intrinsic grounds for ongoing improvement, but also more contextual rationales so that assessment keeps pace with changes in knowledge, curriculum, teaching, institutions, and learning. Christensen and Eyring (2011) document how higher education is undergoing radical change with disruptive innovation at its core. Despite substantial improvement in many parts of higher education, student knowledge and skill is still most commonly measured in the traditional ways characterised above. A narrative flowing across this chapter is that assessment has yet to have its game-changing moment. Whether change is transformational or incremental, however, there are intrinsic grounds for ongoing improvement.

Second, there are strategic institutional rationales for finding innovative ways to assess student learning. Assessment resources and processes signify in non-trivial ways what an institution delivers - variations in assessment imply variations in education and graduates. In an industry dominated by research metrics, assessment offers fresh territory for institutions to showcase education activity and performance (Coates and Richardson 2012).

Third, there is enormous value for institutions, faculty, students and governments in finding cheaper ways to assess student learning. While methods and contexts vary, assessment typically has high fixed and variable costs and limited economies of scale, as with many other facets of conventional higher education 
teaching and learning (for a summary of relevant economics see Coates and Mahat 2014). Increasing cost- and revenue-constraints magnify pressure to develop more efficient forms of assessment without eroding quality. Through one lens, current assessment arrangements can be seen as standing in the path of broader productivity improvements in higher education.

Fourth, concerns about quality are prompting changes in assessment. Through projects such as OECD AHELO (Coates and Richardson 2012) governments signalled that conventional assessment approaches were not delivering required or sufficient information on what students know and can do. As well, more robust assessment would do much to address seemingly persistent employer concerns about graduate capability, if only by clarifying and advancing debate. Educators, too, have taken steps to advance or supplement work in their field (e.g. Edwards et al. 2012; MSC 2014). Quality pressures also provoke the need for more transparency regarding assessment, as in other academic functions.

Fifth, producing more cogent data on outcomes would help prove the returns from education. Currently, important economic debates about education proceed without reference to learning outcomes (DoE 2014; RAND 2014; Sullivan et al. 2012). The broad contribution of higher education is often measured through reference to the production of graduates, and the qualitative difference between graduates counted indirectly via differential employment, or further study outcomes (all else being equal, graduates with better transcripts from more reputable institutions in the field may be expected to secure better work or academic outcomes). The availability of better information on learning makes possible estimation based on the quality of outcomes, not just the quantity of outputs. Indeed, producing reasonable measures of productivity is extremely difficult without valid outcomes data, which carries obvious implications for institutional management and system steering.

Sixth, a further need to improve assessment flows from the limitations of prior quality-related initiatives. As discussed later, in the last few decades a suite of quality initiatives have attempted to address the paucity of information on education, but none have reaped promised change. Institution-level quality audits have failed to yield sufficient information on student learning (Dill 2014; Krzykowski and Kinser 2014). Rankings address partial performance in specific contexts, but focus on research (Federkeil et al. 2012; Van Vught 2012). Competency specification approaches, such as the Tuning Process (González and Wagenaar 2008), have considerable merit, but frame expected rather than actual outcomes. National qualification frameworks began as a move towards competency-based education, but have become policy instruments which often underemphasise specific contexts (McBride and Keevy 2010). Questionnaire-derived metrics (e.g. Coates and McCormick 2014) are valuable, but only deliver proxy information on student learning. Assessment projects have been initiated (Coates and Richardson 2012; Edwards et al. 2012; Canny and Coates 2014), but these have yet to yield required change.

Anyone working in or around higher education recognises that these reform pressures play out in varying ways at different moments, that assessment is only 
part of a very much larger story, and that the above analysis is inevitably broad and incomplete. Yet taken together, these pressures explain more than a little of the need to reform assessment, and hence, spur the need to advance work on assessing learning outcomes.

\section{Taking Stock of Existing Change Initiatives}

The lack of modernisation of assessment is not a result of lack of imagination or effort. In the last few decades many endeavours have sought to unblock the development of assessment. It is helpful to take evaluative stock of the field to showcase recent work and ground the analyses that follow. Clearly, taking critical stock of a field as large and diverse as higher education assessment is a useful though challenging task - there are an enormous number of actors and initiatives, each at varying stages of maturity and diffusion. Rather than conduct an exhaustive review of specific assessment initiatives, therefore it is feasible to survey a series of broad developments which have sought to move beyond routine practice.

Important seeds of a fruitful evaluation lie in finding a helpful frame and appropriate level at which to pitch the analysis. The Assessment Transparency Model (ATM) (Coates and Mahat forthcoming) is deployed as a useful means for reflecting critically on the extent of formalisation and optimisation of assessment without assuming the maturation implies standardisation. Indeed, to avoid subsequent confusion it is helpful at this point to clarify a common misinterpretation of the term 'standards' and its various linguistic derivations. This chapter does indeed argue for the need to improve the standards of assessment design and practice. As in any area, it is contended that enhancing the standards of assessment will encourage diversification and excellence both in terms of education and outcomes. The chapter does not argue for the standardisation of assessment processes, resources or outcomes in everyday education contexts.

The ATM (Fig. 1) blends developmental and activity dimensions. The first dimension marks out a suite of academic phases, with these ordered according to a continuum of increasing transparency. At the foundation level there are 'anarchical' forms of truly collegial practice, reflecting what was characterised above as boutique or traditional forms of work. 'Appreciation' marks the next most transparent phase, reflecting awareness that new academic approaches are available. After this, the 'articulation' phase denotes the explicit documentation of new academic practices in a descriptive or normative sense. 'Application', the penultimate phase, signals that new practices have been actioned. 'Amalgamation' is the final phase, signalling the integration and sharing of academic processes and outcomes. The model charts the maturity of each of these five transparency phases along a second dimension. Each phase can be characterised as being at the formulation stage, the implementation stage, or the evaluation stage.

Building academics' assessment skills and capacity is arguably the most significant intervention. Such work might incorporate supplementary programs for 


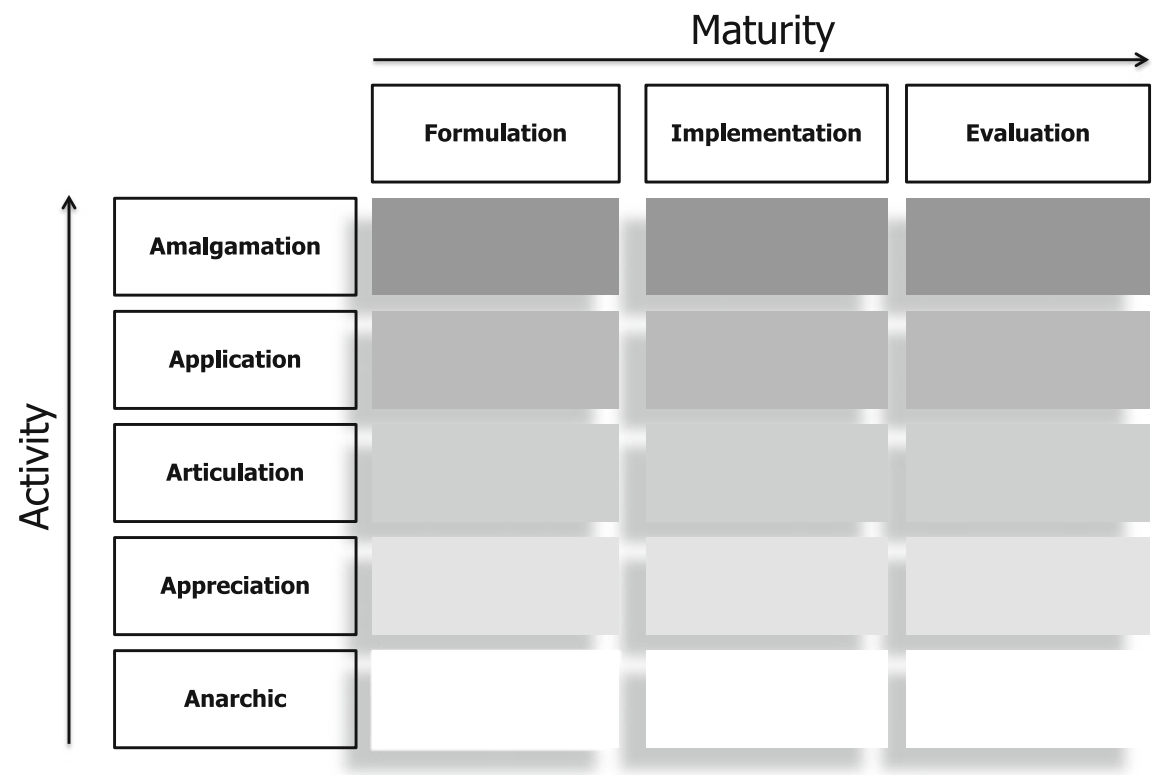

Fig. 1 Assessment transparency model (ATM)

doctoral students, academic professional development, advanced graduate study, or project activities. Even though education is a core pillar of higher education, it would be reasonable to describe the training of prospective or current academics in assessment as spasmodic. Such development has the potential to lift practice beyond anarchy, and build appreciation of student learning and assessing outcomes. With a focus on individual or organisational rather than resource development, such training can tend to fall short of creating clearer articulation of outcome or task specifications, though it may result in diverse forms of applied work, and possibly even instil a milieu for benchmarking and other shared interpretative activities.

One broad line of development has involved specifying qualification-level outcomes. Examples include the European Qualifications Framework, the United Kingdom Subject Benchmark Statements, the Australian Qualifications Framework, and the United States Degree Qualification Profile. As the titles convey, this work is developed and owned by systems, and such initiatives have served as important policy instruments for shifting beyond an anarchic plethora of qualifications, generating conversations about finding more coherence, and indeed articulating the general outcomes graduates should expect from a qualification (Chakroun 2010). These system-wide structures can suffer from unhelpful collisions with fruitfully divergent local practice, but their inherent constraint is that they go no further than articulating very general graduate outcomes. They offer little beyond broad guidelines for improving the assessment of student learning.

Going one step further, a further line of work has sought to specify learning outcomes at the discipline level. The Tuning Process (González and Wagenaar 
2008) is a prominent example which has been initiated in many education systems, and across many diverse disciplines. Broadly, Tuning involves supporting collaboration among academics with the aim of generating convergence and common understanding of generic and discipline-specific learning outcomes. Canada adapted this work in innovative ways, focusing the collaborations around sector-oriented discipline clusters rather than education fields (Lennon et al. 2014), while in Australia a more policy-based and regulatory-focused approach was deployed (ALTC 2010). Such collaboration stimulates appreciation and articulation of learning outcomes, going several steps further than qualification frameworks by engaging and building academic capacity within disciplinary contexts. Like the qualification frameworks, however, the work usually stops short of advancing assessment resources, and tends to focus instead on advancing case studies or best practice guidelines. Hence while it may arise in particular fields, there is no emphasis on the application of common procedures or amalgamation of shared results. In short - there is no 'data on the table'. As well, it must be noted, while the Tuning Process has proliferated internationally there has been little if any summative evaluation, which would add to its traction.

A slightly deeper line of development involves the application of shared rubrics to moderate assessment tasks or student performance. Moderation in assessment can play out in many ways (Coates 2010) as indeed has been the case in recent higher education initiatives. The moderation of resources has involved rudimentary forms of peer review through to slightly more extensive forms of exchange. Mechanisms have also been developed to help moderate student performance. In the United States, for instance, the AAC\&U (Rhodes and Finley 2013) has developed VALUE rubrics for helping faculty assess various general skills. The United Kingdom's external examiner system (QAA 2014) is a further example. Several such schemes have been launched in Australia, including a Quality Verification System and a Learning and Teaching Standards Project, both of which involve peer review and moderation across disciplines (Marshall et al. 2013). This work travels deeper than qualification- or discipline-level specifications, for it involves the collation and sharing of evidence on student performance, often in ways that engage faculty in useful assurance and development activities. Such moderation work is limited, however, in being applied in isolation from other assessment activities and materials. Hence it implies various unsystematic forms of application and amalgamation.

Collaborative assessments build from the developments discussed so far to advance more coherent and expansive approaches to shared assessment. As with other developments addressed here, such work plays out in myriad ways. For instance, medical progress testing in the Netherlands (Schuwirth and Van De Vleuten 2012) involves the formation of shared assessment materials, and administration of these in a longitudinal sense. Other assessment collaborations have focused on the development of shared tasks, analytical or reporting activities (e.g. Edwards et al. 2012; Zlatkin-Troitschanskaia et al. 2014). Such work is impressive as it tends to involve the most extensive forms of outcome specification, task production, assessment administration, analysis and reporting, and at the same time 
develop faculty capacity. Typically it travels far beyond anarchical practice to include various forms of articulation, application and amalgamation. Work plays out in different ways, however, shaped by pertinent collegial, professional and academic factors. This can mean, for instance, that extensive work is done that leads to little if any benchmarking or transparent disclosure.

Standardised assessment is easily the most extensive form of development, and would appear to be growing in scope and scale. Licensing examinations are the most longstanding and pervasive forms of assessment, though their use is cultural and they tend to be far more common in the United States than Europe, for example. A series of graduate outcomes tests have also been trailed in recent years, such as the OECD's Assessment of Higher Education Learning Outcomes (AHELO) (Coates and Richardson 2012), the United States Collegiate Learning Assessment (Shavelson 2007) and the Proficiency Profile (ETS 2014). Standardised assessments are also promulgated via commercial textbooks (Pearson 2014). As the term 'standardised' implies, these assessments tend to tick many, if not all boxes in the top three rows of the assessment transparency model, though given the external sponsorship of such work, often at the expense of engaging with academics, and as part of the process shifting the workforce beyond anarchic to more sophisticated forms of practice. Though such exogenous intervention may in the longer run inject the shock required for reform, it also tends to balkanise internal from external interests and has little impact on learning or teaching practice.

\section{Clearing Barriers to Progress}

Clearly, there are myriad reasons why assessment has not been experienced its game-changing modernisation moment. While such reasons are invariably entwined in specific contexts and initiatives common themes can be isolated from review of several projects. These contextual challenges are considered with respect to the factors required to facilitate change. As with the preceding analysis, there is no claim that the list is exhaustive or the analysis universal. Thinking and practice in certain fields and institutions is more advanced than in others.

Obviously, people with vested interests in entrenched approaches are often significant obstacles to change. Today's higher education leaders and faculty have often made significant institutional and individual investments in conventional assessment resources and practices. At the same time, these are the very professionals who are bearing the brunt of quality and productivity pressures. Reshaping their perspective on assessment would open myriad fresh opportunities. This is a challenging point to make, yet remains a task that cannot be ignored.

Relevant professional capability and capacity is required to change assessment practice, which in the field of higher education is in short supply. Higher education itself lacks dedicated assessment professionals, and there appear to be too few assessment specialists with relevant industry experience (Coates and Richardson 2012). As picked up in the conclusion to this chapter, the lack of a professional 
assessment community is an obvious impediment to change. Building a new profession of assessment experts or a community of faculty with interest in assessment requires investment by higher education institutions and stakeholders, yet can ultimately be addressed through training and development. This has already happened in certain contexts - the United States higher education and medical education are obvious examples-yet there is a need to broaden practice.

Academics require professional training and development to improve competence in assessment, yet such training has really only evolved over the last few decades, and as noted above, is spasmodic. It would be helpful to cite figures on the incidence of such training among academics, and while it affirms the point, it is regrettable that such figures do not exist. Most academics learn their trade via what could be characterised as an informal apprenticeship, and while competence in assessment is no exception, this does not discount the need for creating more systematic forms of professional development. Improving assessment capability among academics will do much to encourage diversification and excellence.

Inasmuch as academic autonomy, in its various encapsulations, provides faculty with a sense of private ownership over assessment it can be a significant impediment to change. Assessment by its nature is a very public and formal matter, and subject to any material constraints should be as transparent as any other academic activity. Research proposals and papers undergo peer review, and there is no reason why assessment tasks should not as well. Academic autonomy is invariably a contingent rather than absolute phenomenon, and it is likely that training and management could advance more sophisticated conceptualisations of professional practice.

Often the most profound shocks are exogenous to a system. The rise of online technology and policies impelling increasing marketization of higher education are two examples. By definition such shocks are highly significant to advancing education, yet are profoundly difficult to forecast or induce. Ultimately, as in many industries, new technologies and business processes are required to adapt.

Inherent security and confidentiality constraints play an obvious role in constraining assessment reform. The greater the stakes, the greater the security and confidentiality implications. In a host of ways such constraints hinder collaboration and drive-up costs, yet contribute to the value and impact of assessment. Engineering new technologies and assessment processes seems to be the most effective means of addressing such constraints.

As assessment like other facets of higher education becomes increasingly commercial in nature, various business considerations grow as greater obstacles to change. Non-trivial intellectual property considerations may be pertinent, for instance, by hindering the sharing and replication of materials. Working through such obstacles can be expensive and complex, yet in many instances is ultimately resolvable with appropriate negotiations and agreement.

It is likely the assessment of student learning doesn't change given its low priority to institutions (surprisingly). From many perspectives the current system seems 'good enough', and besides pressure from accreditation or employers there can appear to be little impetus to change. Data from assessments are not included in 
international institutional rankings, for instance, and academic promotions practices typically favour research over education performance. As these remarks portend, sparking change on this front likely requires an external commercial or regulatory intervention.

Traditional higher education structures can hamper progress, creating confusion about who should own change. Individual faculty focus on assessing particular subjects, departments focus on majors, and students and institutions on qualifications. Fragmentation of curriculum and cohorts can further hinder the formation of coherent assessment schemes. This can create an ownership or agency problem, rendering change problematic. Changing this dynamic typically involves developing and managing more collaborative forms of academic practice.

Academics' belief in the success of current practice is likely to be a major change barrier. Indeed, current practice may well work locally, yet be unsustainable in broader or different contexts. An assessment task may be perfectly aligned with an academic's curriculum and teaching, for instance, yet fail to contribute to the qualification-level information required for external professional accreditation. Institutions have varying ways for leading change in academic practice, which ultimately must resonate with prevailing policies and norms.

In reviewing challenges in changing assessment practice in higher education it appears that change, in summary, hinges on further academic professional development, changed institutional management, ongoing technology and business process development, and external commercial or policy intervention. None of these facilitators are easy to plan or enact. Given the complexity and difficulty of the task to hand, there seems value in pushing on all fronts in synchrony, noting that even by passing through various tipping points, reform is likely to be haphazard and take time.

\section{Making Progress that Counts}

To yield the best outcomes it is essential to invest constrained time and resources in the most effective ways. What, then, are the major processes involved in assessment, and the benefits and challenges of changing each? In essence, what is the assessment supply and value chain, and how can it be improved? The emphasis on value chain (Porter 1985) as well as supply chain heralds the need to focus not just on technical and operational processes, but also on improving the quality and productivity of assessment for students, institutions and broader stakeholders.

Even the handful of very common forms of assessment play out in different ways, and rather than analyse academic activities such as exams or laboratory assignments, it is helpful to delve deeper to investigate more fundamental underpinnings. Key processes are organised into several phases in Table 1. As a way forward the following analysis estimates the quality and productivity benefits that would arise from change in each phase, and the challenge associated with such change. 
Table 1 Generic assessment phases and activities

\begin{tabular}{|c|c|c|c|c|}
\hline Planning & Development & Implementation & Analysis & Reporting \\
\hline Governance & $\begin{array}{l}\text { Mapping } \\
\text { resources }\end{array}$ & $\begin{array}{l}\text { Designing } \\
\text { administration }\end{array}$ & $\begin{array}{l}\text { Collation of } \\
\text { results }\end{array}$ & Production of grades \\
\hline Leadership & $\begin{array}{l}\text { Specifying } \\
\text { outcomes }\end{array}$ & $\begin{array}{l}\text { Organising } \\
\text { facilities }\end{array}$ & Marking & $\begin{array}{l}\text { Analysis and } \\
\text { commenting }\end{array}$ \\
\hline \multirow[t]{5}{*}{ Management } & $\begin{array}{l}\text { Selecting } \\
\text { formats }\end{array}$ & $\begin{array}{l}\text { Managing } \\
\text { students }\end{array}$ & Data production & Reporting \\
\hline & $\begin{array}{l}\text { Drafting } \\
\text { materials }\end{array}$ & $\begin{array}{l}\text { Administering } \\
\text { assessment }\end{array}$ & Cross-validation & $\begin{array}{l}\text { Assessment review and } \\
\text { improvement }\end{array}$ \\
\hline & $\begin{array}{l}\text { Qualitative } \\
\text { review }\end{array}$ & $\begin{array}{l}\text { Resolving } \\
\text { problems }\end{array}$ & & \\
\hline & $\begin{array}{l}\text { Quantitative } \\
\text { review }\end{array}$ & & & \\
\hline & $\begin{array}{l}\text { Material } \\
\text { production }\end{array}$ & & & \\
\hline
\end{tabular}

Assessment is underpinned by various forms of strategic and operational planning, which leads to specific governance, leadership, and management arrangements. Effective strategic planning is the key to improvement, of course, not least to build greater institutional rather than individual engagement in assessment to ensure higher-order capabilities are being assessed and more coordinated approaches to improvement. Operational planning is an area in which there would appear to be substantial grounds for development. Analysis reported elsewhere (Coates and Lennon 2014) suggests that collegial forms of governance appear most effective, though there is value in strengthening existing practice by adding further points of external reference. As earlier remarks convey, there would appear to be substantial benefit in adopting more advanced management of assessment, which appears to be instrumental in shifting practice beyond boutique forms of practice.

Assessment development hinges on a suite of technical, substantive and practical considerations, but fundamentally involves specification, development, validation of materials, as well as planning for their deployment. This is an area in which there are enormous quality and productivity advances to be made in re-engineering conventional practice. As discussed earlier, work is underway in particular fields and contexts on finding more collaborative and scalable approaches to specifying learning outcomes. This is important, for specifying learning outcomes is the work that links curriculum with assessment. Less advance has been made in improving the specification of concrete assessment tasks, however, with much practice still relying on convention rather than more scientific rationales. Similarly, there would appear to be substantial advance possible regarding assessment task productionfeasibility has been demonstrated in large-scale initiatives, but diffusion of new techniques has been low. As well, research findings (see Coates 2014) affirm the need to improve the validation and production of materials. In short, beyond advances regarding definitional work, the development phase of assessment is almost entirely in need of reform. 
Assessment implementation, like development, is an area in which reform would contribute significant value to higher education. As noted throughout this chapter, much assessment is delivered in highly dated ways which is particularly surprising given radical changes in other facets of higher education. This application of new technologies would appear to be instrumental for reform, as would better embrace of professional experts and organisations. Alignment with innovations in teaching may be fruitful. If specialist independent organisations can deliver assessment better and cheaper than higher education institutions, then expanding outsourcing will doubtless be seen by university executives as one among other feasible futures for this facet of higher education. As well, on transparency grounds there would appear to be value in moving beyond individual delivery to introduce more peer-reviewed or otherwise quality-assured forms of delivery. Obviously, the implications of such change for academic leadership, academic work and academic learning are in need of profound and imaginative reflection (Coates and Goedegebuure 2012). While such ideas may appear to collide with traditional beliefs about academic autonomy and more recent institutional competition and commerce, other facets of higher education have transformed in far more radical ways to the advantage of higher education.

The analysis and reporting phases involve significant administrative and technical work, and as with the development and implementation phases have the potential to benefit substantially from transformation. Faculty time is a major cost-driver in higher education, and particularly given the lack of specialist expertise regarding assessment, there is value in finding approaches that make the most prudent use of available resources. While various forms of peer review have been deployed via moderation systems that offer a form of cross-validation, for instance, other forms of verification exist that don't require additional faculty resources. Substantial value would be added in any effort that further aligns assessment feedback with teaching and learning practice.

\section{Assessment Redesign-A Tactic for Reform}

In summary, it is concluded in this chapter that the quality and productivity of higher education would be improved by reforming almost every facet of assessment. Much assessment may be excellent and efficient, but most is not. Clearly, by this analysis extensive change is required which may seem overwhelming to plan or initiate. Much small- and large-scale work has proven the feasibility of change, yet substantial obstacles hinder the diffusion of reform. As the chapter has asserted, this is a difficult and messy area of higher education in which there are no perfect solutions. All approaches have advantages and limitations.

Building a program of work on 'assessment redesign' offers a way forward. Such work could adapt relevant existing institutional and governmental work (Nicol 2014; O'Neill and Noonan 2011; Twigg 2003). To be effective it would need to work across multiple levels and engage faculty, institutional managers and leaders, 
and relevant external stakeholders. Such work would need to dovetail with broader curriculum, workforce or other reform, though this is not essential and this chapter has asserted an independent need for assessment reform. To engender broad appeal and necessary faculty engagement assessment redesign must be easy to understand and implement, yet yield meaningful improvement.

Framed within the broader context of teaching and learning, a compelling research paper that resonates with both policy and practice is required to spark modernisation work on assessment redesign. Such work would in essence involve detailing:

- contexts and rationales driving the need for reform, elaborating those in this chapter;

- primary assessment activities such as those in Table 1;

- assessment support activities - typically infrastructure, human resources, technology and procurement;

- robust yet parsimonious processes for identifying cost drivers, and for reducing costs; and

- quality and value criteria, and mechanisms for assurance and differentiation.

To have impact it is essential to carefully articulate the audience for this formative contribution. Clearly, to gain initial traction, the research paper must resonate with policymakers and institution leaders. But it must also resonate with faculty and academic managers, for the discussion in this chapter has affirmed that reform will be muted unless faculty change. Importantly, it is likely that the research paper will need to create and speak to a new audience. Looking broadly across various recent initiatives, serious assessment-related work on learning outcomes has been conducted by government officials, university academics, or researchers working in not-for-profit or commercial firms. Such hybrid arrangements are inevitable in the early days of technological adoption, but in synch with the development of the field it is necessary to produce a new kind of higher education assessment expertise and workforce.

With relevant infrastructure in place it would be feasible to review the primary and support activities with reference to the likelihood of working through each of the obstacles sketched above, and for each activity to estimate the costs and benefits for quality and productivity. Improvement resources could then be channelled in the most effective ways - nominally into reforming those activities where change looks feasible, and is likely to yield greater quality or productivity returns. The context and focus of the review would of course shape the recommendations made, and while these would be highly specific, a suite of case studies and collaborative supports could help streamline designs and plans for change. Building this modernisation program, however, is a substantial undertaking in itself, but given its potential to advance assessment, hence higher education, appears to be a worthwhile investment to make. 
Open Access This chapter is distributed under the terms of the Creative Commons Attribution Noncommercial License, which permits any noncommercial use, distribution, and reproduction in any medium, provided the original author(s) and source are credited.

\section{References}

Australian Learning and Teaching Council (ALTC). (2010). Learning and teaching academic standards project final report. Sydney: Australian Learning and Teaching Council.

Canny, B., \& Coates, H. (2014). Governance Models for Collaborations Involving Assessment. Sydney: Office for Learning and Teaching.

Chakroun, B. (2010). National qualification frameworks: From policy borrowing to policy learning. European Journal of Education, 45(2), 199-216.

Christensen, C., \& Eyring, H. J. (2011). The innovative university: Changing the DNA of higher education from the inside out. New York: Wiley.

Coates, H. (2010). Defining and monitoring academic standards in Australian higher education. Higher Education Management and Policy, 22(1), 1-17.

Coates, H. (2014). Higher education learning outcomes assessment: International perspectives. Frankfurt: Peter Lang.

Coates, H., \& Goedegebuure, L. (2012). Recasting the academic workforce: Why the attractiveness of the academic profession needs to be increased and eight possible strategies for how to go about this from an Australian perspective. Higher Education, 64(6), 875-889.

Coates, H., \& Lennon, M. C. (2014). Propelling the field: Insights, trends and prospects. In H. Coates (Ed.), Higher education learning outcomes assessment: International perspectives. Frankfurt: Peter Lang.

Coates, H., \& Mahat, M. (2013). Assessing student engagement and outcomes: Modelling insights from Australia and around the world. International Journal of Chinese Education, 2(2), 241264.

Coates, H., \& Mahat, M. (2014). Threshold quality parameters in hybrid higher education. Higher Education, 68(4), 577-590.

Coates, H. \& Mahat, M. (forthcoming). Clarifying progress: Validation and application of the assessment transparency model (ATM).

Coates, H., \& McCormick, A. C. (2014). Engaging university students: International insights from system-wide studies. Dordrect: Springer.

Coates, H., \& Richardson, S. (2012). An international assessment of bachelor degree graduate's learning outcomes. Higher Education Management and Policy, 23(3), 51-69.

Dill, D. D. (2014). Ensuring academic standards in US higher education. Change: The Magazine of Higher Learning, 46(3), 53-59.

Department of Education (DoE). (2014). The College Scorecard: College Affordability and Transparency Centre. Retrieved from: http://www.whitehouse.gov/issues/education/highereducation/college-score-card

Edwards, D., Wilkinson, D., Coates, H., \& Canny, B. (2012). The Australian medical assessment collaboration: Developing the foundations for a national assessment of medical student learning outcomes. Sydney: Office of Learning and Teaching.

Educational Testing Service (ETS). (2014). Proficiency profile. Retrieved from: www.ets.org/ proficiencyprofile/about

Federkeil, G., Van Vught, F., \& Westerheijden, D. (2012). Classifications and rankings. In F. Van Vught \& F. Ziegele (Eds.), Multidimensional ranking: The design and development of U-multirank. Dordrecht: Springer.

González, J., \& Wagenaar, R. (2008). Universities' contribution to the Bologna process: An introduction. Bilbao: Universidad de Deusto. 
Krzykowski, L., \& Kinser, K. (2014). Transparency in student learning assessment: Can accreditation standards make a difference? Change: The Magazine of Higher Learning, 46(3), 67-73.

Lennon, M. C., Frank, B., Humphreys, J., Lenton, R., Madsen, K., Omri, A., \& Turner, R. (2014). Tuning: Identifying and measuring sector-based learning outcomes in postsecondary education. Toronto: Higher Education Quality Council of Ontario.

Marshall, S., Henry, R., \& Ramburuth, P. (2013). Improving assessment in higher education: A whole of institution approach. Sydney: New South Books.

McBride, V. \& Keevy, J. (2010). Is the national qualifications framework a broken promise? A dialogue. Journal of Educational Change, 11, 193-203.

Medical Schools Council (MSC). (2014). Medical schools council assessment alliance. Retreived from: http://www.medschools.ac.uk/MSCAA/Pages/default.aspx

Nicol, D. (2014). Re-engineering assessment practices in higher education. Retrieved from: www. reap.ac.uk

O'Neill, G. \& Noonan, E. (2011). First year assessment redesign-a program approach. Retrieved from: www.ucd.ie/teaching/resources/assessment/firstyearassessment

Pearson. (2014). MyEconLab. Retrieved from: www.pearsonmylabandmastering.com/ northamerica/myeconlab

Porter, M. (1985). Competitive advantage: Creating and sustaining superior performance. New York: Simon and Schuster.

Quality Assurance Agency (QAA). (2014). The UK quality code for higher education. Retreived from: www.qaa.ac.uk.

RAND. (2014). Learning gain in higher education. Cambridge: RAND Europe.

Rhodes, T., \& Finley, A. (2013). Using the VALUE rubrics for improvement of learning and authentic assessment. Washington: AAC\&U.

Schuwirth, L. W. T., \& Van De Vleuten, C. P. M. (2012). The use of progress testing. Perspect Med Educ, 1(1), 24-30.

Shavelson, R. (2007). A brief history of student learning assessment: How we got where we are and a proposal for where to go next. Washington: Association of American Colleges and Universities.

Sullivan, T. A., Mackie, C., Massy, W. F., \& Sinha, E. (2012). Improving measurement of productivity in higher education. Washington: National Academics Press.

Twigg, C.A. (2003). Improving learning and reducing costs: New models for online learning. EDUCAUSE Review(September/October), 28-38.

Van Vught, F. (2012). Diversity, transparency and institutional profiling in higher education. Paper presented at the LH Martin Institute Symposium on Strategic Differentiation and Sameness in Australian Higher Education: Institutional Profiling and Transparency, Melbourne.

Zlatkin-Troitschanskaia, O., Kuhn, C., \& Toepper, M. (2014). Modelling and assessing higher education learning outcomes in Germany. In H. Coates (Ed.), Advancing higher education learning outcomes. Frankfurt: Peter Lang Publishers. 